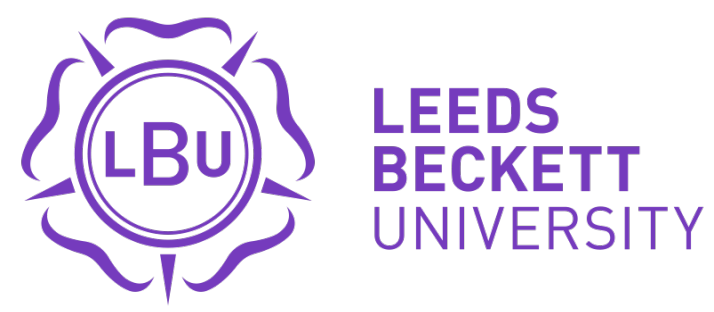

Citation:

Dart, J (2014) Sports review: A content analysis of the International Review for the Sociology of Sport, the Journal of Sport and Social Issues and the Sociology of Sport Journal across 25 years. International Review for the Sociology of Sport, 49 (6). 645 - 668. ISSN 1012-6902 DOI: https://doi.org/10.1177/1012690212465736

Link to Leeds Beckett Repository record:

https://eprints.leedsbeckett.ac.uk/id/eprint/945/

Document Version:

Article (Accepted Version)

The aim of the Leeds Beckett Repository is to provide open access to our research, as required by funder policies and permitted by publishers and copyright law.

The Leeds Beckett repository holds a wide range of publications, each of which has been checked for copyright and the relevant embargo period has been applied by the Research Services team.

We operate on a standard take-down policy. If you are the author or publisher of an output and you would like it removed from the repository, please contact us and we will investigate on a case-by-case basis.

Each thesis in the repository has been cleared where necessary by the author for third party copyright. If you would like a thesis to be removed from the repository or believe there is an issue with copyright, please contact us on openaccess@leedsbeckett.ac.uk and we will investigate on a case-by-case basis. 


\title{
Sports review: A content analysis of the International Review for the Sociology of Sport, the Journal of Sport and Social Issues and the Sociology of Sport Journal across 25 years
}

Jon Dart

\begin{abstract}
The International Review for the Sociology of Sport, the Journal of Sport and Social Issues and Sociology of Sport Journal have individually and collectively been subject to a systematic content analysis. By focusing on substantive research papers published in these three journals over a 25-year time period it is possible to identify the topics that have featured within the sociology of sport. The purpose of the study was to identify the dominant themes, sports, countries, methodological frameworks and theoretical perspectives that have appeared in the research papers published in these three journals. Using the terms, identified by the author(s), that appear in the paper's title, abstract and/or listed as a key word, subject term or geographical term, a baseline is established to reflect on the development of the sub-discipline as represented by the content of these three journals. It is suggested that the findings illustrate what many of the more experienced practitioners in the field may have felt subjectively. On the basis of this systematic, empirical study it is now possible to identify those areas have received extensive coverage and those which are underresearched within the sociology of sport. The findings are used to inform a discussion of the role of academic journals and the recent contributions made by Michael Silk, David Andrews, Michael Atkinson and Dominic Malcolm on the past, present and future of the 'sociology of sport'.
\end{abstract}

Keywords: Academic journals, content analysis, research, sociology of sport, trends, Wordle

This paper reports findings from a systemic study of the content of three journals that serve the sociology of sport. The task was to undertake a comprehensive review of the substantive content of the International Review for the Sociology of Sport (IRSS), the Journal of Sport and Social Issues (JSSI) and the Sociology of Sport Journal (SSJ). Whilst those with a long-standing association to the field will have a personal, anecdotal impression of which themes, sports, methods and theories have been prevalent, I sought to move beyond the individual and impressionistic and offer an assessment of the sociology of sport over a 25-year time period based on the content of these three journals. The aim of the exercise was to identify areas of interests and reflect on those that have been well served and those that have received only fleeting attention. Academic journals should not be seen as representing the entirety of the 'sociology of sport', but they are the primary medium for its formal academic communication. Before outlining the rationale for selecting these three particular journals, the raison d'etre of all academic journals is to publish research to the wider (academic) community and, along with textbooks and conferences, seek to legitimise the intellectual development of the discipline (Heck and Cooley, 1988), assess scholarly discourse and move the conversation forward. Tomlinson (2006) suggests academic journals are the 'life-blood of the discipline', whilst Spender's (1981) feminist critique of the 'codification of knowledge production' sees them as significant power bases. The influence of academic journals is far-reaching, not least in their use by teaching staff to introduce content to the next generation of scholars. Journals have taken on growing significance in securing tenure and influencing promotion in the USA, and in the UK's Research Assessment Exercise (RAE) and the Excellence in Research for Australia (ERA) rankings.

The sociology of sport is based on the relationship between sport, culture and society and has always been an open, interdisciplinary field that has sought to incorporate elements from education, philosophy, social psychology, history and economics. In seeking to assess the health of any discipline there needs to be regular and critical self-examination. Although comment will be made 
on each journal and their individual 'footprint', the intention here is not to censure or compare, but to aggregate their content, present the data and offer reflection on the development of the subdiscipline as a whole. By analysing the content of three leading academic publications over a 25-year time period, the intention is to establish a baseline from which to perform such self examination. The hope is that the data will show the past 25 years as a period of dynamic and diverse research activity in the sociology of sport.

There has been a steady stream of 'state-of-the-field' papers narrating the development of the sociology of sport, often authored by people central to the evolution of the sub-discipline. Writing in the IRSS, Coakley (1987: 76) suggested that, based on a content summary of papers published in the first 14 issues of the SSJ, 'American authors show that sociology of sport research in the United States emphasises descriptive and 'issue-related' quantitative studies rather than qualitative or theory based studies'. Others have tracked the evolution of the sociology of sport as a sub-discipline (Atkinson, 2011; Ingham and Donnelly, 1997; Krawczyk, 1990; Loy and Sage, 1997; McPherson, 1975; Rowe et al., 1997; Silk and Andrews, 2011; Silk et al., 2010), its related professional associations and conferences (Greendorfer, 1987; Melnick and Sabo, 1987), with Nixon's (2010) commentary on the relationship between North American Society for the Sociology of Sport (NASSS) and academic programmes of study in the USA being a recent contribution. 'Heinemann and Preuss's (1990) content analysis of the IRSS (for the period 1966-1989) found that since the journal's inception during the 'Cold War' there had been a distinction between researchers working in the Soviet socialist regions of Europe and those working in North America and Western Europe. In his editorial celebrating the 40th anniversary of the IRSS, Donnelly (2005) noted that Volume 1 contained authors from 13 countries, covering three continents (with Eastern and Western Europe featuring most often), with a single paper from a female academic.

More recently, in his discussion of the historical development of the sociology of sport, Malcolm (2012) argues that many of these state-of-the-art reviews were authored by people central to its history and that such commentaries should not be seen as 'simply cultural neutral, "factual", recordings of history', but instead as necessarily selective and revealing of particular interests, biases and motives. Malcolm (2012) highlights how previous state-of the art reviews suggested changing trends in terms of dominant theoretical approaches, with a functionalist paradigm replaced by a Millsian-informed Marxist approach, and subsequently Gramscian-informed cultural studies. Rapid changes across the higher education sector globally and the particular changes being enacted in UK universities (Collini, 2012; Hussey and Smith, 2010) are fuelling discussion on the current state and future direction of the sub-discipline. For Silk et al. (2010) these changes are creating an environment in which greater emphasis is given to evidence-based research with less likelihood of the political and critical potentialities offered by the sociology of sport being advanced. The past, present and future of the 'sociology of sport' has been questioned by Atkinson (2011) and Silk and Andrews (2011). Suggesting that a 'debilitating blend of introspective and ineffectual parochialism ... has plagued the Sociology of Sport', Silk and Andrews (2011: 5) claim that the sociology of sport has become increasingly nebulous and will not survive as a sub discipline within a wider, hostile neoliberal atmosphere. In its stead, they propose a 'physical cultural studies' (PCS) programme with 'the active body' as its focus. Initially motivated by a desire to avoid mid-career routinisation, academic torpor and fear of redundancy, they want to see 'committed scholars ... push the envelope of research engagement, public communication [and] knowledge representation' (Atkinson, 2011: 138). The proposed PCS agenda and Malcolm's (2012) paper prompted this study, with their proposals revisited after presentation of the data. In an attempt to identify the main areas of interest in the field, as represented in the selected journals, and to complement previous state-ofthe-art reviews, this study will collate the content of three journals over a 25 -year time period to address five overarching research questions: 
- What are the dominant topics and areas of inquiry that feature in the academic journals that serve the sociology of sport?

- Which sports have received attention from sports sociologist?

- Which country/countries have featured in the research?

- Which method/methodology has been prevalent in the field?

- Who/what are the theorists/theories being utilised in the research?

In preparing to undertake a content analysis, one can choose any number of issues to explore. The rationale for selecting these journals and these particular topics was a desire to move away from a wholly subjective, impressionistic assessment of the 'state-of-the-field' as critiqued by Malcolm (2012), and offer an assessment based on somewhat more objective data. The original aim of this study was to offer a purely objective assessment using the author-written abstract, key words, subject terms and geographical terms. However, for reasons discussed later, this was not possible and it was therefore necessary to adopt a more interpretive approach. After briefly outlining the three selected journals, an account of the research methodology is given, before presentation of the findings.

\section{The journals}

The expansion of higher education and the profits generated from journal publications have significantly increased the number of academic journals (Altbach and Rapple, 2012). The sociology of sport can, arguably, be seen as an inclusive discipline that is open to a plurality of positions in terms of method and theory found therein. It has served as a major feeder discipline for a large number of university sports degree courses and is linked to a wide range of disciplines, including education, cultural studies, history, media studies, politics, philosophy and economics. Consequently, those seeking to publish research on sport from a sociological standpoint can chose from a wide range of journals. In addition to the three journals reviewed here, mainstream sociology journals are increasingly willing to receive sports-themed papers; equally, there are many other less sociologicalfocused journals that explore the relationship between sport and education, culture, history, media, the body, psychology, management and policy. 'Sociology' appears in the titles of the IRSS and the SSJ, and is implicit within the JSSI. Given the growing range of possible outlets, the rationale for this study was to select leading, international journals whose remit centred on the sociology of sport.

The selected journals operate primarily from a social science base, but are interdisciplinary with research papers often informed by anthropology, cultural studies, economics, ethnic studies, geography, gender studies, history, leisure studies, management, media studies, political economy, psychology and semiotics. The Sport in Society journal was considered for inclusion, but was omitted due to its predilection for producing special themed editions (which are often converted into books); it was felt that so many themed editions might distort the data. The selected journals are all peer reviewed and written in English language; however, each has a different history and geographical location that inform its format and content. The intention was not to 'fault' or compare the three journals, but to form an impression of each journal's content and, by implication, identify the areas of interest in the wider sub-discipline.

When it appeared in 1966, the International Review of Sport Sociology was the first journal to focus on the sociology of sport. With origins in the International Committee for Sociology of Sport, the early focus was on physical education and sociology. In 1983 it moved from Poland to West Germany and changed its title to the International Review for the Sociology of Sport (Heinemann and Preuss, 1990). In 1997 Sage became the publishers, with the journal's link to International Sociology of Sport Association (ISSA) maintained. It appeared annually between 1966 and 1973, after which it was published quarterly and in 2012 began to be published bi-monthly (Donnelly, 2005). As with the 
other journals included in this study, it is interdisciplinary in its theoretical and methodological approach. Where it differs is in its remit to publish work from across the international academic community, as befits its links with the ISSA.

The first issue of the JSSI appeared in 1977, building on the success of the Arena Review, which itself drew inspiration from Jack Scott's Institute for the Study of Sport and Society (see Goldstein, 2000; Moore, 2000). Originating in the Center for the Study of Sport in Society (CSSS), the JSSI is the official journal of Northeastern University's Center for the Study of Sport in Society. The original foci of the Arena Review were political economy, women, race, medical abuse, athletes' rights, and the impact of sport on communities (Lapchick, 1977). In 1993 the JSSI increased from a bi-annual publication to tri-annual; it currently appears quarterly and, along with the IRSS, holds an impact factor.iii The journal positions itself as interdisciplinary with its stated aim and scope being to stimulate debate about theoretical assumptions and methodological approaches. Although attempting to become be a more international journal, the focus remains on North America.

The origins of the SSJ lay in a bi-annual, two/three-page newsletter (Review of Sport and Leisure), which appeared in response to a concern that existing academic conferences were not offering a serious sociological analysis of sport. The NASSS held its first conference in Denver in 1980 and in 1984 members voted to produce a quarterly journal, inviting Human Kinetics to be its publisher (Greendorfer, 1987). In the first volume, the Editor (Jay Coakley) sought to establish links with the wider sociology discipline and attract papers from outside North America. It currently appears four times each year. The content of a journal will often depend on the personal predilections of its editor, (Aitchison, 2001; Spender, 1981), who has the ability to set agendas, parameters and act as a gatekeeper to the discipline. Whilst an editor can solicit papers, create themed editions, invite guest editors and appoint individuals to the editorial board they are, to an extent, dependent on the papers submitted by researchers 'in the field'. However, the positional biases held by individual peer reviewers and those invited to join a journal's editorial board should not be underestimated in terms of their potential to shape the field. The working assumption is that an editor will invite an expert to review a research paper, but due to their workloads, they are often unavailable, potentially leaving a less qualified individual a 'free shot' at critiquing the work of a peer. It is the case that referees are accountable only to the editor, with the submitting author having little meaningful 'right of reply' (Mumford, 2012). What is changing the game is the arrival of open-access journal publishing and the significant impact it is making across all areas of the humanities and sciences.

\section{Methodology}

The aim of this research is to systematically, quantitatively and thematically audit the content of these three journals. Content analysis is used as the research method and, as Stemple (1981: 119) has explained, it is 'a formal system for doing something that we all do informally rather frequently'. Multiple analysis techniques are available under the umbrella term 'content analysis' (David and Sutton, 2011; Silverman, 2003), with researchers selecting from a number of techniques (Bishop, 2007; Kian et al., 2009; King, 2007; Messner et al., 2000; Millward, 2008; Vincent, 2004; Vincent et al., 2010).

After identifying the units to be sampled (i.e. the journals - whose selection was explained previously), the next step was to identify the unit of text. A decision was made to include only original, peer-reviewed, full length research articles and/or communications, extended commentaries, perspectives and invited contributions. Book reviews, editorials, journal introductions, annotate bibliographies, conference announcements or reports were not included. The primary data were retrieved from online databases and were printed and sorted to remove those units of text that did not fit the inclusion criteria. 
- IRSS: papers from 1984 (volume 19/1) to the end of 2011 (Volume 48/4) were included. This generated 644 items for coding.

- JSSI: papers from 1977 (Volume 1/1) through to the end of 2011 (Volume 35/4) were included. This generated 614 coded items for coding.

- SSJ: papers from 1984 (Volume 1/1) through to end 2011 (Volume 29/4) were included.

This generated 681 items for coding.

A total of 1939 items were identified as for suitable for coding. Units of analysis were then identified as the title of the paper, the abstract, key words, subject terms and geographical terms, from which a coding scheme and codebook were developed. The printouts were used as the coding form and manually coded for each of the five categories identified previously. A pilot study (involving precoding and data analysis) of over 600 papers was undertaken to identify and check the suitability of the categories and to construct the research protocol, coding scheme and codebook. Central to undertaking a content analysis are the issues of consistency, validity and reliability in the coding process (Krippendorff, 2004; Riffe et al., 1998). To ensure consistency, all the coding was undertaken by the author, using the codebook for reference. The coding scheme was based on a system of categories and sub-categories, with the material coded being the manifest content (i.e. words in the title, abstract and/or listed as a key word).

As noted earlier, the original intention of this study was to undertake a wholly objective assessment of the three journals' content; however, the pilot study revealed in excess of 300 categories in the 'themes'. .v Given the vast number of emergent categories, it was not possible to conduct a wholly objective study. Therefore, it was necessary to undertake data reduction and, using the relevant function in SPSS software, recode certain variables (i.e. words and terms) to make the data manageable. As there was no limit on the number of codes given to each paper for any of the five categories, not every variable was coded where there was overlap; for example, when the words 'neo-liberal capitalism', 'government' and 'policy' appeared in the same paper they were coded once under the thematic category of 'politics/economics'. Attempts were made to code for ethnicity and demographic variables; however, it soon became apparent that these were less solid categories, with too many 'unknowns' on the information presented in the abstract and key word listings. The overriding intention of the study was to secure a broad-brush identification of the dominant themes, sports, countries, methods and theories that feature in the three journals.

When preparing a paper for submission to a journal, it is necessary to acknowledge that an author might seek to be strategic in the choice of words that appear in the paper's title, abstract, or selection of key word, subject term or geographical term. With the arrival of online search and retrieval options, some authors seek to achieve as many 'online hits' as possible and increase the potential for their research to be cited by others. One is also cognisant of the limited word count accorded to the abstract and how journal publishers limit the number of key words allowed, with default choices potentially limiting the scope of the paper's content. A reliance on key words alone would act to essentialise and compartmentalise the research carried out and reported in the paper. It was therefore necessary to also utilise the words that appeared in the title and abstract. These units of analysis were chosen on the basis that they would give a fairly accurate description of the likely content of the paper. It might be that certain themes were contained within the paper, but if they were not stated in the title or abstract, or listed as a key word, then I have not been able to capture them. This might be seen as a limitation of the study and should therefore be borne in mind when reviewing the findings.

Once the manual coding had been completed, the data were entered into the IBM SPSS Statistical 19 package for descriptive statistical analysis. Frequency distribution tables were used to tabulate, describe and summarise the properties of the data. In this paper, the results are presented using 
Wordle (IBM), an open source text-mining software tool freely available via the web. ${ }^{\vee}$ Wordle visual represents text data as a word (data) cloud with its presentation format widespread in popular media and beginning to appear in academic journals (Uprichard, 2012). Wordle uses word frequency to establish different weightings, with the words presented in different font sizes to indicate numerical value: that is, the larger the font, the more times the word appeared. In this paper, this visually descriptive methodology is used to identify the dominant themes, sports, countries, methods and theory that appear the journals that serve the sociology of sport. ${ }^{\text {vi }}$ Although Uprichard (2012: 3) notes that Wordle is easy to use and fast, requires no specialist knowledge and with 'a few simple tweaks allows for relatively sophisticated analysis to be conducted', it has been criticised for its crudity (Harris, 2011). Despite these reservations, this form of visualisation does invite consideration as to why certain words stand out and reflection on a number of issues pertinent to the sociology of sports and academic publishing.

While Wordle and other emerging software visualisation tools are widely used in the popular media, their value (notwithstanding Uprichard's (2012) study) in academic journals is untested. More detailed information presented within traditional numerical tables and graphs might have been expected (and more familiar to an academic audience) and would similarly have provided for interesting scholarly discussion. Totals have been included in the discussion of specific Wordle figures; however, precise totals are not always shown due to the 'fuzzy' nature of some of the coding. It is recognised that a lack of actual quantification (i.e. raw numbers) does mean that comparative studies or a repetition of this study in 10 years will be difficult, but Wordle is used for the reasons identified above.

\section{Findings}

\section{Themes}

The IRSS contained 46 main themes and, as can be seen from Figure 1, these are fairly well distributed. The JSSI had 42 themes, with certain themes dominating (Figure 2). The SSJ had a comparable 45 themes, with a slightly more equal distribution amongst its leading themes (Figure 3 ). It should be noted that the intention here is not to make a value judgement on, or between, the journals, but to note the interesting indicators expressed by the prevalence of certain themes. The themes of elitism, participation and physical activity/exercise all featured well in the IRSS and the SSJ, but less so in the JSSI. The themes of education and race/ethnicity featured much more strongly in the two North American journals than the IRSS. Two other notable differences are how the JSSI featured celebrity/hero and management, and the IRSS on violence. What is perhaps surprising is the high number of papers that list psychology in the abstract or listed as a key word; this was particularly so in the SSJ, and indicates the long-standing contribution of psychology (including social psychology) within the sub-discipline of the sociology of sport, especially in North America.

Figure 1: International Review for the Sociology of Sport - Themes 


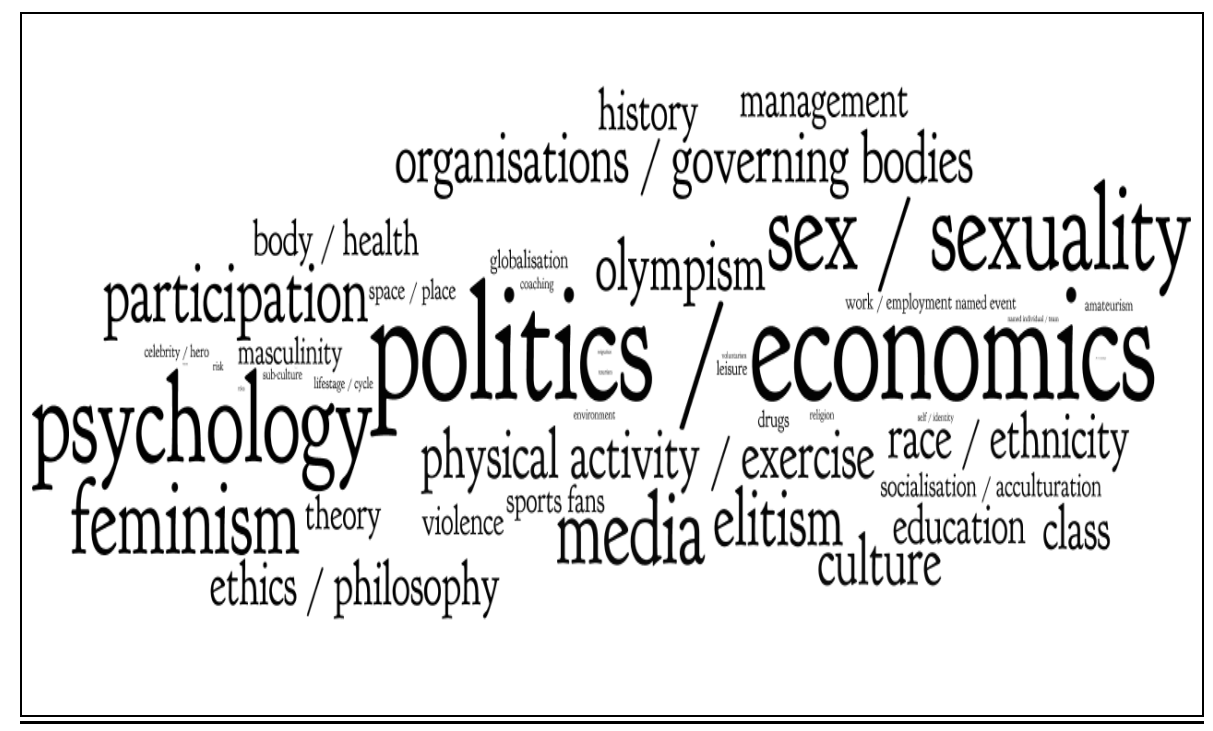

Figure 2: Journal of Sport and Social Issues - Themes

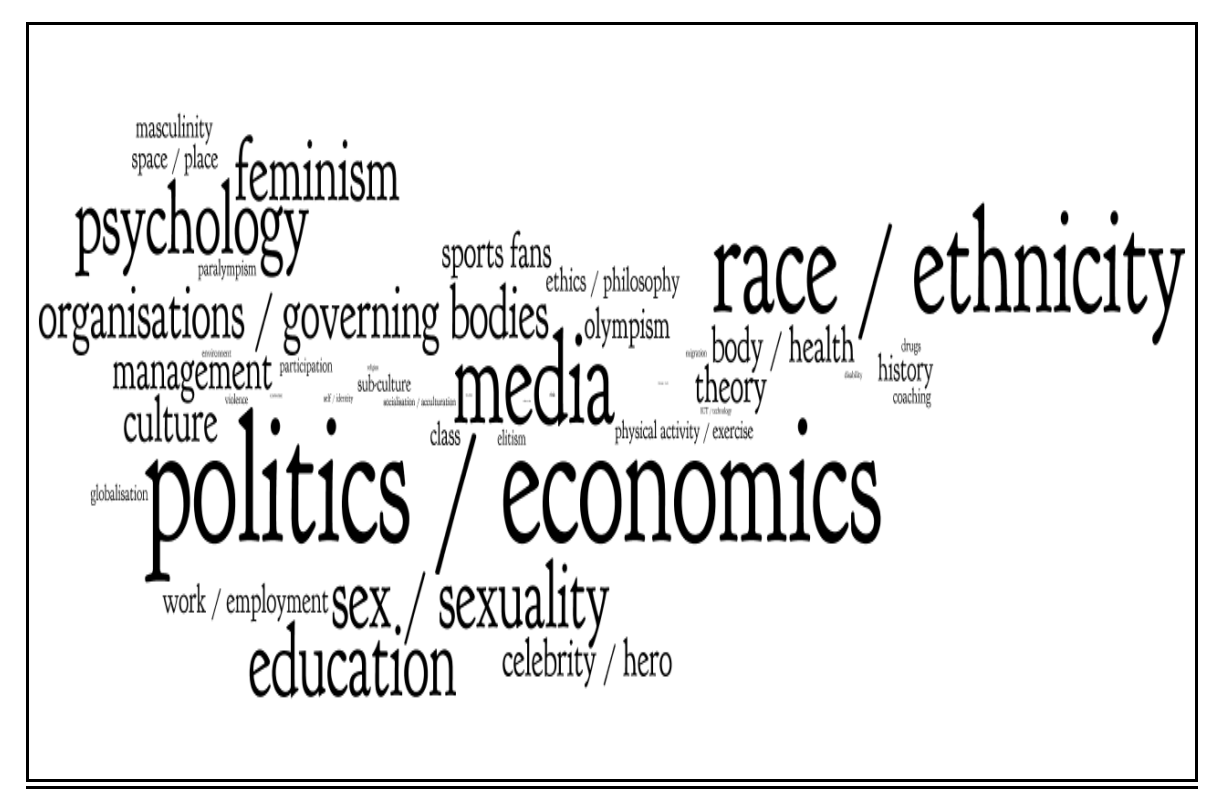

Figure 3: Sociology of Sport Journal - Themes 


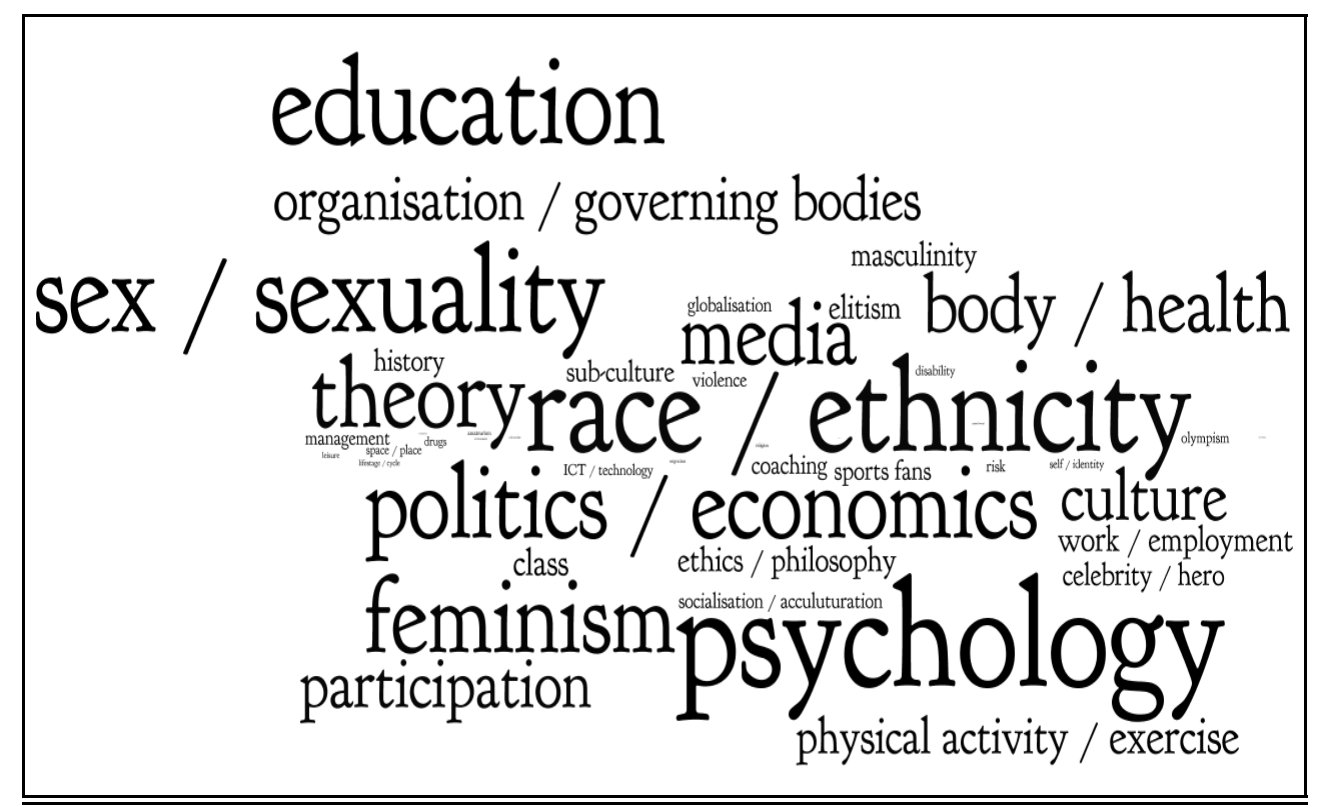

Figure 4: Themes (combined from three journals)

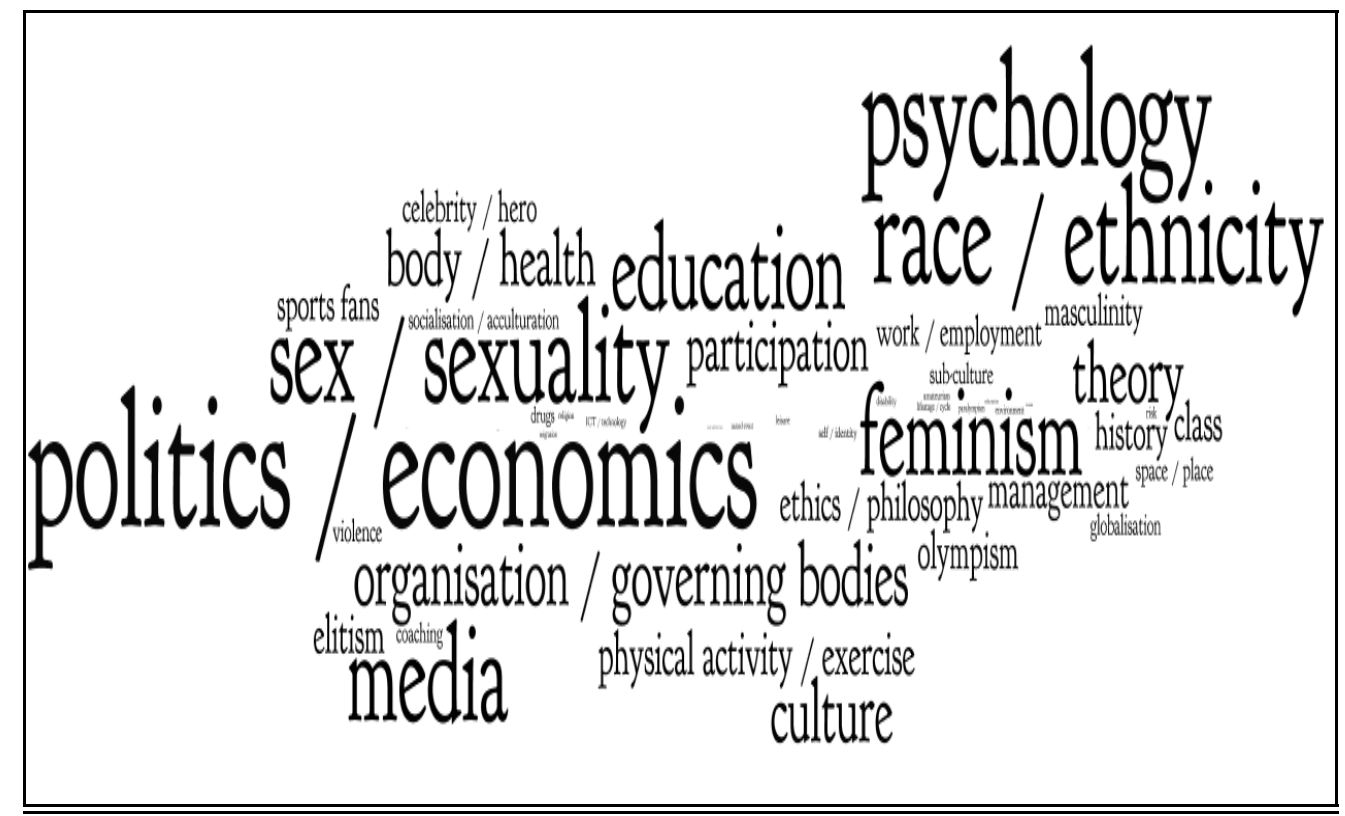

There is a broad consensus in the main themes with a very similar 'top 10' across the three journals. What is noticeable is that all the core sociological concepts ('usual suspects') feature prominently: that is, gender [coded here separately as sex/sexuality, feminism and masculinity], race/ethnicity, education, media, politics and economy and globalisation. Class also features but less frequently. There is limited identification of other core sociological concepts, including religion, the family, the environment, and work/employment.

On a personal level, I did not anticipate the low level of research on ICT/technology, volunteering, disability and the environment. Again, revealing a personal preference, I would have expected history to feature more in the overall results (it was placed 19th in the overall listing of themes in 
three journals), see Figure 4. I would have anticipated theory to have featured more strongly; it does not appear that the sociology of sport is disappearing into a theoretical abyss: far from it, with theory being well represented in the SSJ, but much less so in the JSSI and the IRSS. Theory is discussed separately below.

\section{Sports}

The IRSS has featured 52 different sports, with four sports appearing more than 10 times. As Figure 5 shows, soccer dominates, featuring four times more than the next sport of basketball. Given soccer's identification as a 'global game', its prevalence in an international journal is to be expected. The two other sports that feature more than 10 times are cricket and Rugby Union. Twenty-two sports and activities feature only once, including the popular sports of fishing, snooker and triathlon. The JSSI features 50 sports, with seven appearing more than 10 times (soccer, baseball, basketball, NFL, golf, tennis and boxing), see Figure 6. Rodeo features twice, with 17 sports appearing only once (including Frisbee, bird-watching and Australian Rules Football). The SSJ features 49 sports, with eight appearing more than 10 times (baseball, basketball, soccer, NFL, middle and long-distance running, ice hockey, rugby union and tennis - see Figure 7). For a North American journal it was surprising to see the inclusion of papers on the Gaelic Athletic Association (GAA) and Highland Games. Sixteen sports feature just once.

\section{Figure 5: International Review for the Sociology of Sport: Sports}

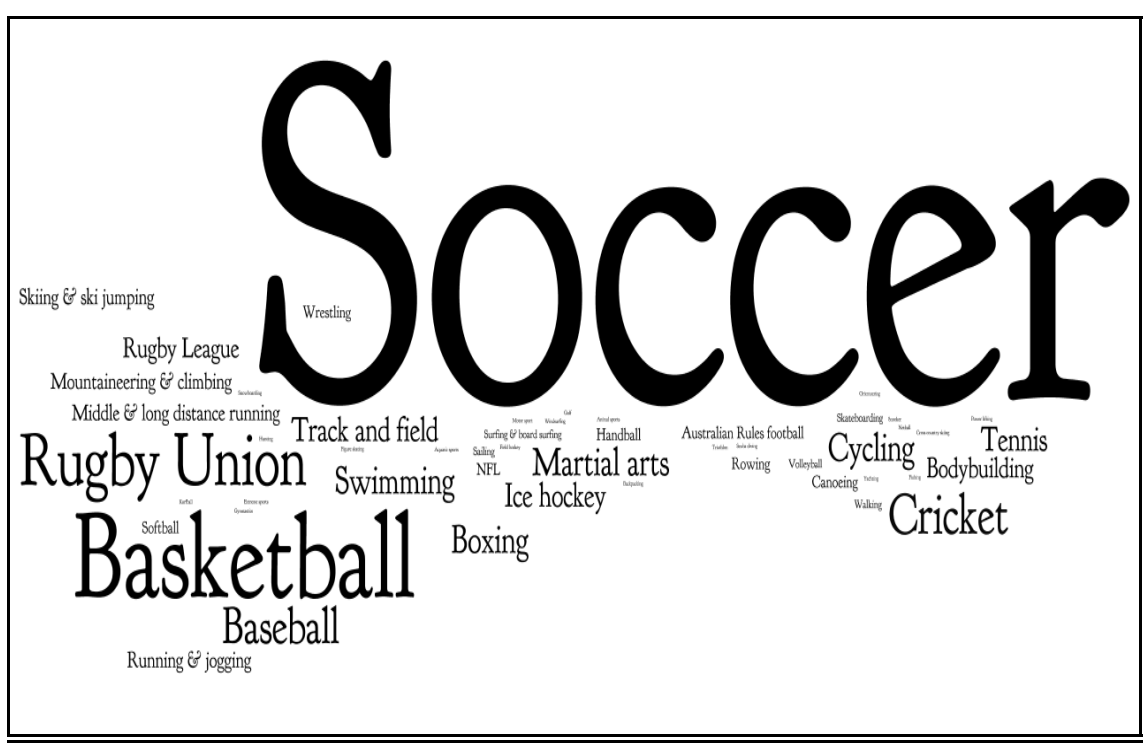

Figure 6: Journal of Sport and Social Issues: Sports 


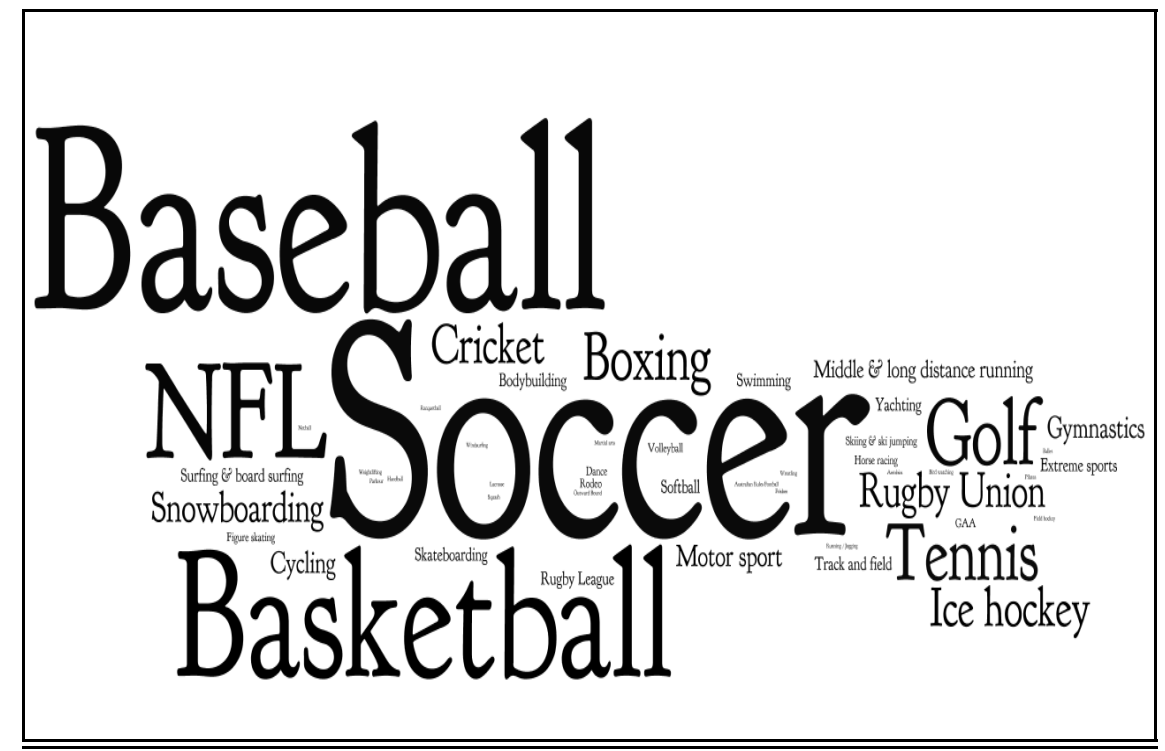

Figure 7: Sociology of Sport Journal: Sports

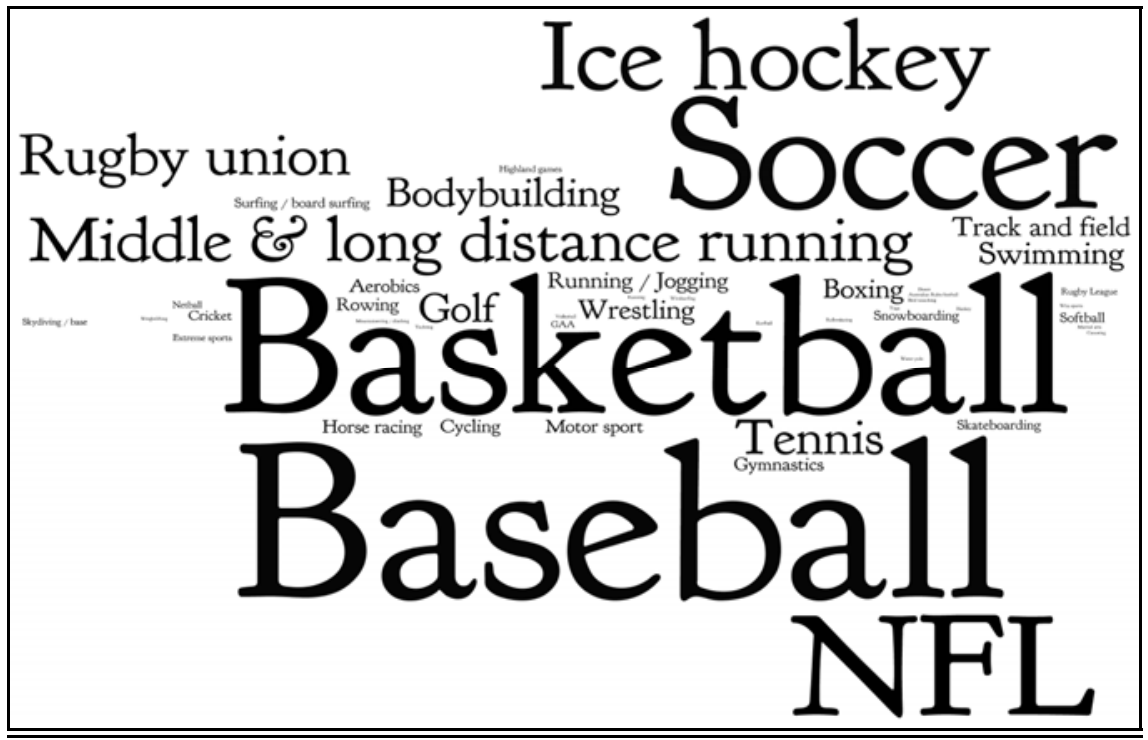

A total of 74 sports and activities are identified across the three journals (see Figure 8). The most popular sports are those involving teams, but there are examples of individual sports and activities (e.g. running and bodybuilding). What is evident is how 'sport' (as identified in the journals' titles) encompasses a broad range of activities - ranging from fun, amateur, school, competitive to elite levels, as well as related leisure activities. The three journals are remarkably similar in terms of the total number of sports featured (specifically 52,50 and 49 , respectively). There is also similarity in the dominant sports that feature in the JSSI and the SSJ. The main differences are that hockey and rugby union feature prominently in the SSJ, whilst the JSSI featured golf and boxing. Aggregating the sports that feature in the three journals, it is noticeable that some extremely popular sports feature very minimally (i.e. equine sport and fishing). New forms of sport do appear, although research on ethnic/indigenous sports is rare. 


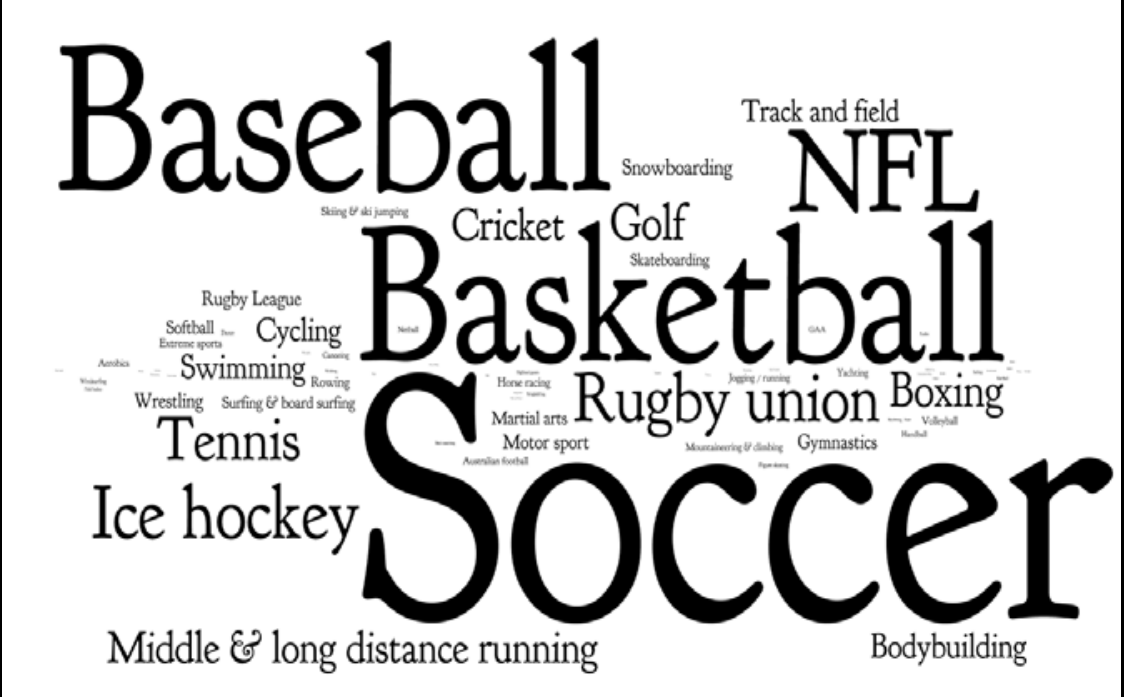

\section{Country}

In addition to using the title, abstract, key words and subject terms, research articles were also coded using 'geographical terms'. This was not necessarily where the author was based, but which country (or region) featured in the paper. Countries were only coded where there was a clear identification with no assumptions being made by the coder. The absence of an identified country/region does suggest the paper was focused on the USA. Typically, countries were only identified when they were 'other', so it is suggested that, if anything, the USA (and UK) showing is under-reported.

The JSSI features research on 35 different countries and six regions (see Figure 10). The USA dominates much of the research, appearing almost six times more than second featured country (i.e. Britain/England). Canada, South Africa and Australia are the only other countries to reach double figures. The appearance of South Africa is due to it featuring heavily in the early days of the journal (i.e. the 1980s) when South Africa was an apartheid state (see Coakley, 1987). Thirteen countries feature only once. SSJ features 38 countries and five regions, with five countries appearing more than 10 times (see Figure 11). The USA dominates, being twice as much as the Canada and Britain/England. The pattern is of a North American axis supported by the UK and Australia. 


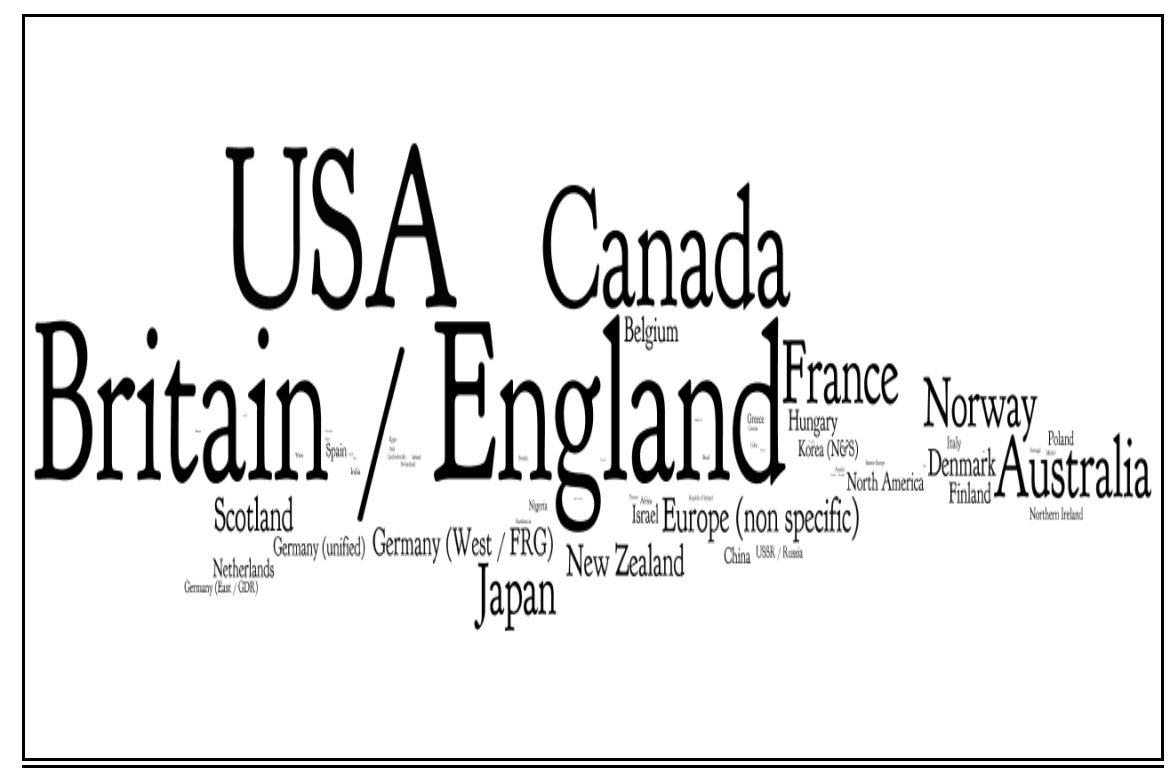

Figure 10: Journal of Sport and Social Issues: Country

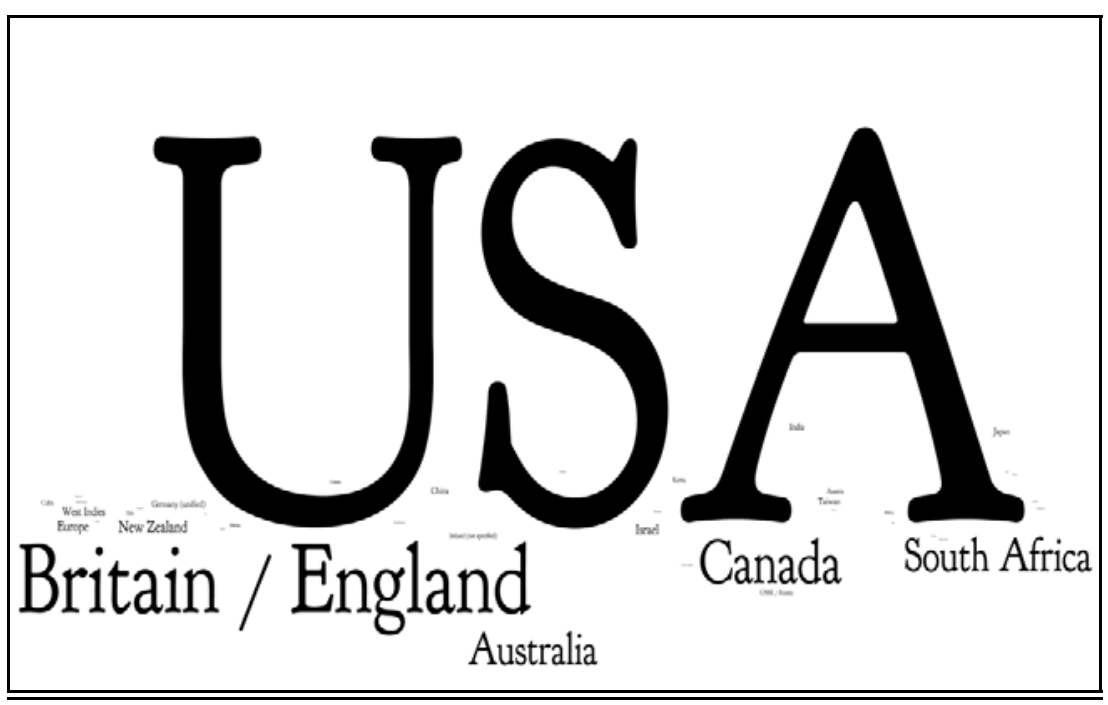

Figure 11: Sociology of Sport Journal: Country 


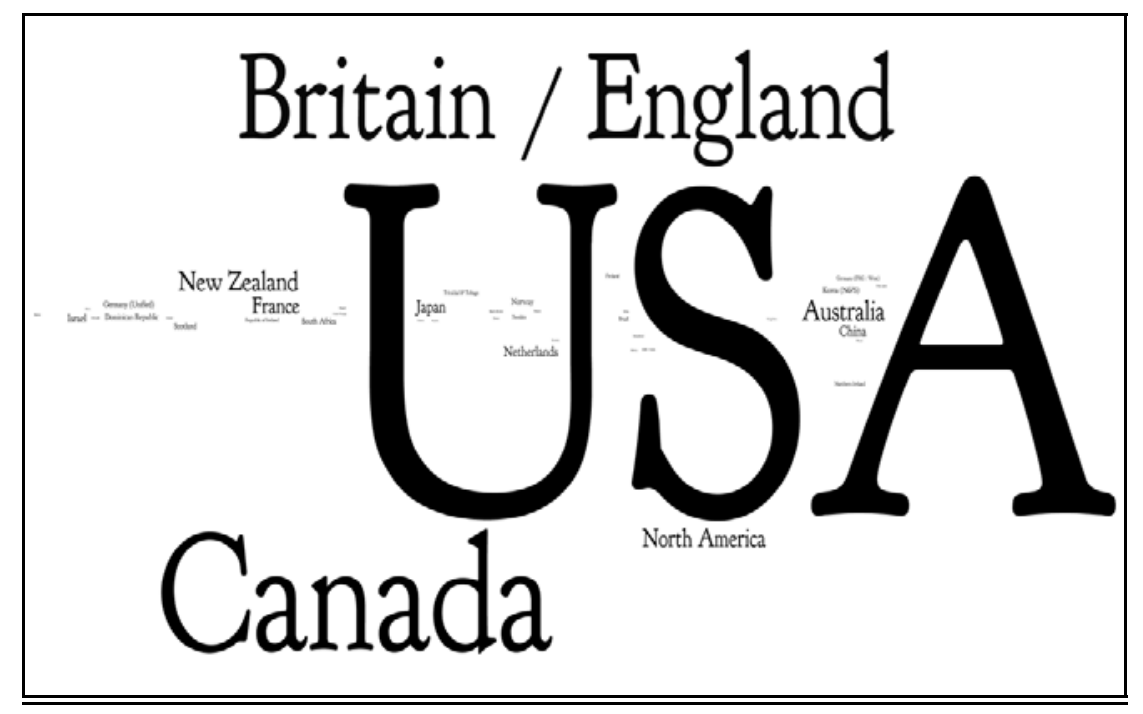

The IRSS features 52 countries and 11 regions (e.g. Latin America, Africa - see Figure 9). Twelve countries feature more than 10 times, and another 12 countries appear just once. In terms of the UK/GB/England relationship, research that focused on England did not automatically state this was the case. This is due to English researchers being unused to having to identify their region of interest, unlike those conducting research in Scotland, Wales and Northern Ireland, who would identify their geographical area of research. If the IRSS papers that identified England, Scotland, Wales and Northern Ireland were aggregated, they would supersede the USA by some 20 papers. Whilst there was a dominance of papers featuring the USA, Britain and Canada in the IRSS, as befits its international remit, other non-English-speaking countries do feature, including France, Japan, Norway, Denmark, Belgium and Germany (which was coded three times: FDR, GDR and reunified). Forty-seven papers included research involving more than one country (typically the USA and Canada), with some 33 papers adopting a regional perspective.

Overall, the dominant geographical areas of interest are the English-speaking regions of North America, the UK and Australia. Of course, papers submitted to these journals are principally written by academics working in North America and UK who, typically, will be conducting research that reflects regional/national interests. It can also be argued that a journal can only publish what is submitted, with the editors and the editorial boards often reflecting this geographical arrangement. Developing countries are moderately represented, with a noticeable under-representation from the BRIC countries (Brazil did not feature on its own; Russia did feature but little since the break-up of the Soviet Union; India has featured a couple of times in the IRSS; whilst China features occasionally, often in relation to the Beijing Olympics).

The findings presented here suggest that comparatively few papers are based on research that seeks to move outside national borders and make trans-national links. The increased sense of globalised world led Stoddart (1989: 125) to suggest that 'we are now more aware of cultural diversity inherent within world sports practices - a benefit both from learning about those practices themselves and from being able to draw comparative conclusions'. Cross-national research informs awareness of cultural diversity within sport, leading one to question the low levels of exposure to 'foreign practices', which would allow comparative assessment(s) to be made. No attempt is made to apportion blame, but we do need to avoid the discipline becoming ethnocentric in terms of its geographical remit and the sports featured. 
Contributing to the health of any discipline is the utilisation of a range of empirical social research methods. There was no straightforward narrative here as this category difficult to code in that it was not always clear from the title, abstract or key words which method(s) had been employed. The absence of an identified method in the title, abstract, etc., does not mean that that the paper was not empirically based; however, it does indicate the author's view of the perceived role and importance of the data collection process. A paper might have been coded for multiple methods, and although some papers did identify a 'mixed method' approach, where individual methods were specified, these were coded individually.

A review of the IRSS shows 351 papers (out of 644 reviewed $=55 \%$ ) with a clearly identified methodology / method. The JSSI contains 247 papers (out of $614=40 \%$ ) with a clearly identified methodology / method. The SSJ has 404 papers (out of $681=59 \%$ ) with an identified methodology / method. Given the relatively low level of an identified methodology it was not possible to undertake a longitudinal analysis of the different methods employed over the 25 -year time period. This lack of data acts to limit the value in offering a visual representation for each journal; therefore, Figure 12 offers an aggregated representation of the methods and methodologies identified across the three journals. As Figure 12 shows, whilst there was a diversity of methods identified, one can see there are distinct preferences for certain methodologies. In terms of quantitative and qualitative approaches, it was not possible to offer a comment on this due to the fluidity of interpretation associated with terms such as content analysis, survey and questionnaire. However, what is evident is the popularity of the desk-top method, with content analysis being the dominant approach, in contrast to long-term studies. As in its parent discipline there is an on-going debate about the relationship between, and use of, quantitative and qualitative research methods (Byrne, 2012; Williams et al., 2008). Given the broad-brush approach adopted in this study it was not possible to identify any trends and it is therefore suggested that further research is needed that offers a more focused analysis of the methods employed and methodologies adopted. As Savage and Burrows $(2007,2009)$ note, one challenge facing sociologists is the need to rethink methodological practices in radically innovative ways, given the emergence of 'knowing capitalism' (Thrift, 2005). In addition, researcher are now sensitised and subject to the increasingly restrictive ethical approval needed (especially in North America), which can act to limit research innovation and possibilities.

Figure 12: Methodology / methods (combined)

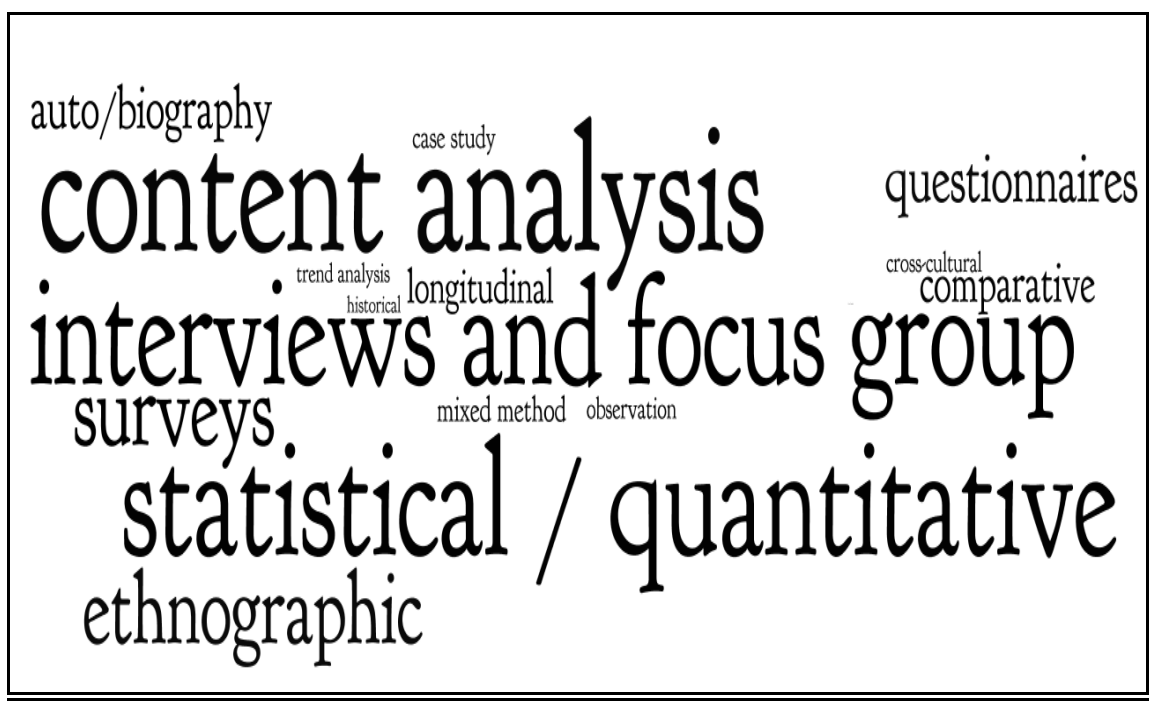


The use of words in the title, abstract and key words did potentially mean that a paper's methodology and/or method(s) were not always explicitly identified and therefore not captured in this study. It might be that the vast majority of papers published did offer an account of their methodological position and/or method(s) used. However, determining these for every paper published over a 25-year time period across three journals would be an enormous task and one for others to attempt. However, what might be more realistic to attempt is a sub-study that examines, for example, the first five years and the last five years of an extended period of time to identify any changes in the direction of the field. However, such an approach would itself be methodologically problematic.

\section{Theory/theorists}

Similar to the classification of methods, a lack of detail in the title, abstract and key word listings made the task of systematically collating and presenting a theoretical typology very difficult. As noted immediately above, one might justifiably assume that the majority of papers did employ a theoretical framework and, therefore, a more subtle tool of analysis is needed to identify trends. Notwithstanding, papers were only coded if there was explicit identification of a specific theoretical approach in the title or abstract or listed as a key word. The initial codebook contained 132 codes for specific theorists/ theoretical approaches, which were subsequently distilled to a slightly more manageable 119 codes. An attempt was made to reduce this number further by seeking to group 'fellow travellers' and align them to a broader theoretical approach. However, this soon became problematic, especially when one recalls Bairner's (2007) discussion of the use (and misuse) of Gramsci, and the reluctance of post-modern theorists to identify with anything beyond themselves. Any non-identification in the title, abstract or key word list is not to suggest that the paper did not engage with theory, but similar to the coding for methodology, the absence of a clearly identified theoretical framework does suggest it was not a central feature in their paper.

Figure 13: Theory / theorists (combined)

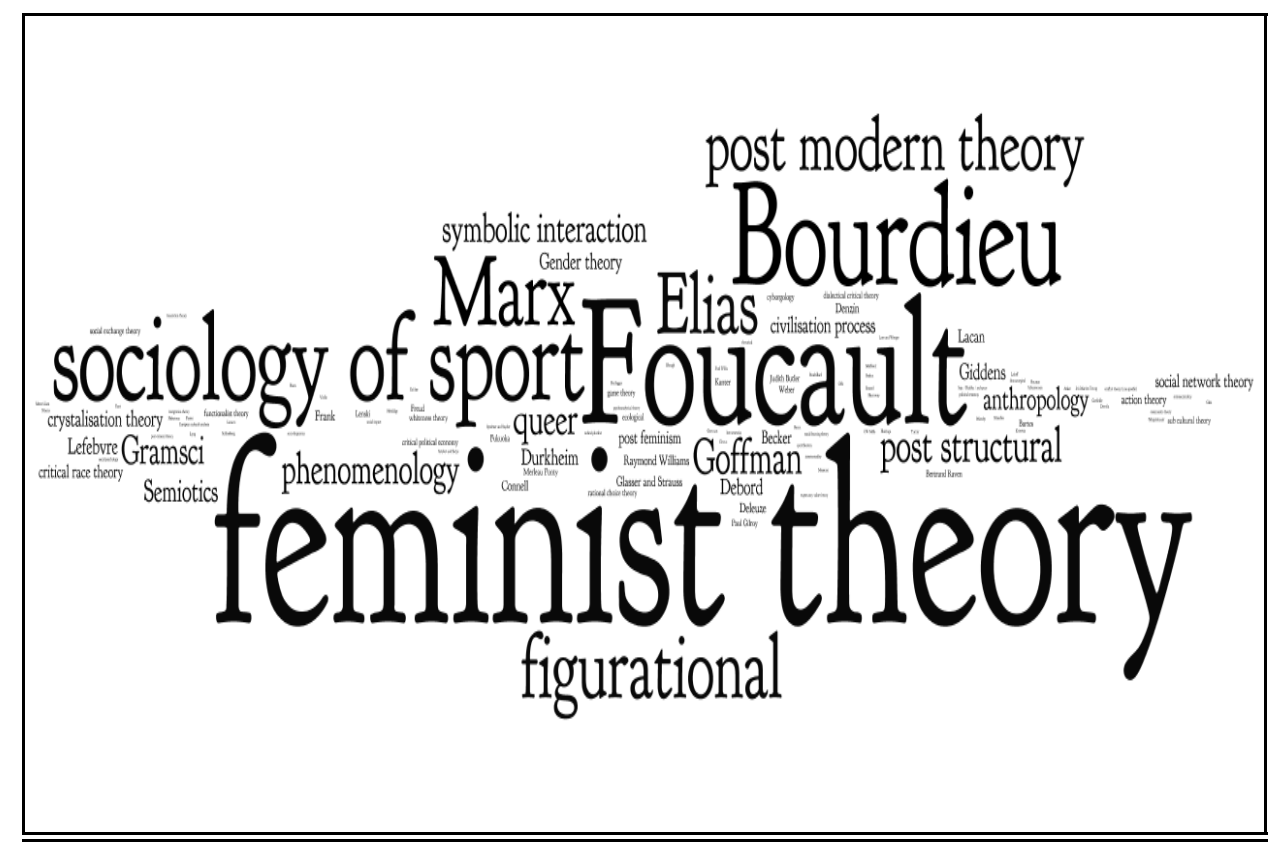

The IRSS has 151 papers in which the author(s) explicitly identifies a theory/theorist, which as a percentage of the papers coded is $23 \%$. Fifty-four different theories/theorists are identified, with the most popular being Bourdieu and Elias, Feminist and Figurational theory. Twenty-nine 
theories/theorists made a single appearance in the journal. The JSSI contains 81 papers that explicitly mention a theory/theorist which, out of 614 papers reviewed, is $13 \%$. Fifty-three different theorists are identified, with 36 featuring just once in the journal (the most popular being Feminist and postmodern theory and Foucault). The SSJ contains 181 papers that explicitly mention a theory, which out of 681 is $27 \%$. Seventy-one different theorists are identified (the most popular being Feminist theory, Foucault, Bourdieu and Marx); 42 theory/theorists appear just one time in the journal. When data from three journals are combined, a total of 14 theories/theorists appeared more than five times, whilst 64 appear only once (see Figure 13). I had hoped to identify longitudinal changes in the use of theory, but similar to the Method/methodology section above, insufficient data was available to offer a trend analysis or determine any 'paradigm shifts' over the 25-year period. Given how the sociology of sport is a sub-discipline of sociology, and the journals being interdisciplinary, the wide range of different theorists could have been anticipated.

\section{Ethnicity and demographics}

There was the intention to code for ethnicity and demographic variables. However, these two categories were the most difficult to code. Thus, the comments here are far more impressionistic than was intended at the outset of the research study. The category Caucasian rarely appeared, with ethnicity noted only when there was a focus on 'nonwhite' ('other') participants. A similar issue arises with gender, with women specifically identified, whereas males (as 'normal') usually went unnoted. Males were rarely identified (as a key word/subject term), with it being seen as implicit and thus not needing coding. Examples of this can be seen in research papers on professional sports teams and athletes, football fans and hooligans and boxing, which typically did not specify that the participants were male (although one could perhaps have assumed this); in contrast, female boxers and football fans were identified by gender. Similarly, able-bodied people were not identified as such, but disabled people were listed as a key word. This is not a criticism of the research, but does illustrate how we still operate with a normative model, only seeking to identify when the 'other' is present.

By way of a small compensation, it is hoped that the thematic coding, which includes 'race/ethnicity' and 'feminism'/'masculinity', can give an indication of the ethnic and demographic foci of the research. It is notable that papers coded from the earlier period did use the key word Hispanic American on research involving African Americans; similarly, a paper on the baseball player Joe DiMaggio used the key word Hispanic American. There was recognition of indigenous peoples (for example, Australian aborigines), with Native Americans appearing most often in research that focused on badges of North American sports teams. From a British standpoint, there was very little research on British Asians. In terms of demographic variables, men, women and young people are all well represented. However, what is evident is how families and retired/elderly/old(er) people received very little attention from researchers.

\section{Discussion}

This paper has collated, reviewed and presented data involving over 1900 research papers that have appeared in three leading journals that have served the sociology of sport over a 25 -year time period. The intention is not to make judgement on the quality of the papers, compare the journals nor criticise their content, but rather to identify the quantity of research topics, sports, countries, methods and theories identified within individual research papers. In his assessment of the historical development of the sociology of sport, Malcolm (2012) highlights how many previous state-of-theart reviews offered a personal narrative of the changing trends within the discipline. As Malcolm (2012) went on to note, many of these reflections were often selective commentaries, informed by particular interests, biases and motives. What I sought to do was to use the available data to offer a less subjective assessment of the discipline by focusing on the content of three leading journals as stated in the title and abstract and listed as a key word. 
Advocates of PCS suggest that 'sociology is sport' has died and offer PCS as its potential successor (Silk and Andrews, 2011). They identify a range of commentaries made by sociologists of sport which, although critical of neo-liberalism, are what Mills (1959) saw as 'critics without claws'. In a spirit of collegiality they invite discussion on the PCS agenda, which they see as predicated on understanding, critical reflection and intervention to make a difference: but is this not what good (i.e. critical) sociology is, or at least should be? This study shows that a wide range of issues have been discussed under the umbrella of the 'sociology of sport'; the strong showing of politics and economics (along with education, race and ethnicity, sex and sexuality, media, organisations and governing bodies) shows researchers engaged in the classic sociological tradition in identifying and discussing how power and ideology are manifested in difference and inequality.

Sociology has faced discrimination as a legitimate field of study within and outside the academy (BSA/ESRC, 2010). The sociology of sport has faced a steeper uphill struggle to establish itself within sociology, constituting what Carrington (2010: 7) sees as a 'double marginality'. Atkinson (2011) has suggested that mainstream sociologists are puzzled by the academic merit of the sociology of sport, whilst Silk et al. (2010) note how the Higher Education Funding Council for England (HEFCE) commented on academics who research 'trivial' or 'pointless' subjects that have 'no relevance to the real world' - identifying one such subject as 'sport'. vii With humanities across the board being undermined by an aggressive neo-liberal agenda, more confidence is needed, especially by sociologists of sport, on the value of their topic, with greater efforts needed to get research beyond the journals and contributing to wider public debates. Open-access journals may offer one such opportunity for sharing research and increasing debate across disciplines and outside the academy, thus advancing Burawoy's (2004) call for 'public sociology'.

As Andrews (2008) has noted, there has been the emergence of a powerful neopositivist health agenda within many university kinesiology/physical activity/sport and health departments wherein research protocols are governed by traditional 'scientific' methods, with funding coming from the private, profit-seeking sector (see also Atkinson, 2011). The important contribution the sociology of sport can make, not least in the study of sport from the physical science disciplines, is necessary given their tendency to neglect the individual and the social; however, the sociology of sport should not be seen as a handmaiden to the sport sciences. The two cultures of art and sciences discussed by CP Snow show how humanistic and scientific study are different in important ways. Snow's approach to the 'two cultures' needs to be engaged with in order to reduce the growing divide between the two; there is much to be gained from working together and showing the unique contribution the humanities and sciences can make to the study of sport and society.

Before concluding, it is necessary to restate the highly influential role played by the editor, editorial board and peer reviewers; it is not possible to know how many papers were rejected (and on what basis); that said, this paper is an analysis of what has appeared, not what has not appeared. What would be useful would be research that explores the process of journal production and the dynamic between editors, peer reviewer(s) and the process of refereeing a paper. Mumford (2012) has suggested that the existing peer review process is deeply flawed, not least in its inherent conservatism with editors and referees reviewing papers based on their own intellectual proclivities and a presumption that they will seek to protect particular views and/or theories. Offering a range of suggestions on how to improve the refereeing process, Mumford (2012) suggests that in seeking greater accountability and transparency, the names of the referees should be included when the paper is published (as happens in many medicine and mathematics journals). However, one anticipates significant issues around access and sensitive egos; after all, we all swim in the same part of the ocean. What is needed is a sustained exchange of ideas about the future role of the journal and the peer-review process, not least with the arrival of open-access publishing. 
The wide range of themes and sports, albeit with a narrower range of countries and methods, suggests there has been engagement with the fundamental questions on the role of sport in society. This is despite the impending, insidious RAE in the UK, the spectre of 'impact' criteria in the forthcoming Research Excellence Framework (REF) and the increasingly restrictive codes being advanced by ethical committees and their potential to restrict innovative research topics and methods (Atkinson, 2011; Bairner, 2009; Callinicos, 2006; Webster, 2006). Similarly, there is the continuation of the 'publish or perish' culture in which tenure and promotion is based on one's publications (Colquhoun, 2011; Fanelli, 2010). The increasingly restrictive audit culture created by neo-liberalism is making itself known by promoting (and funding) an environment wherein the only knowledge that counts is 'concrete evidence' (Jump, 2012; Smith and Meer, 2012), and with greater emphasis being given to evidence-based research there is a potential decline in the political and critical potentialities offered by the sociology of sport (Silk et al., 2010). One challenge, amongst many, for those researching within the sociology of sport will be to resist the emerging, politically driven, audit culture and targets.

Figure 14: The 'footprint' of the three journals

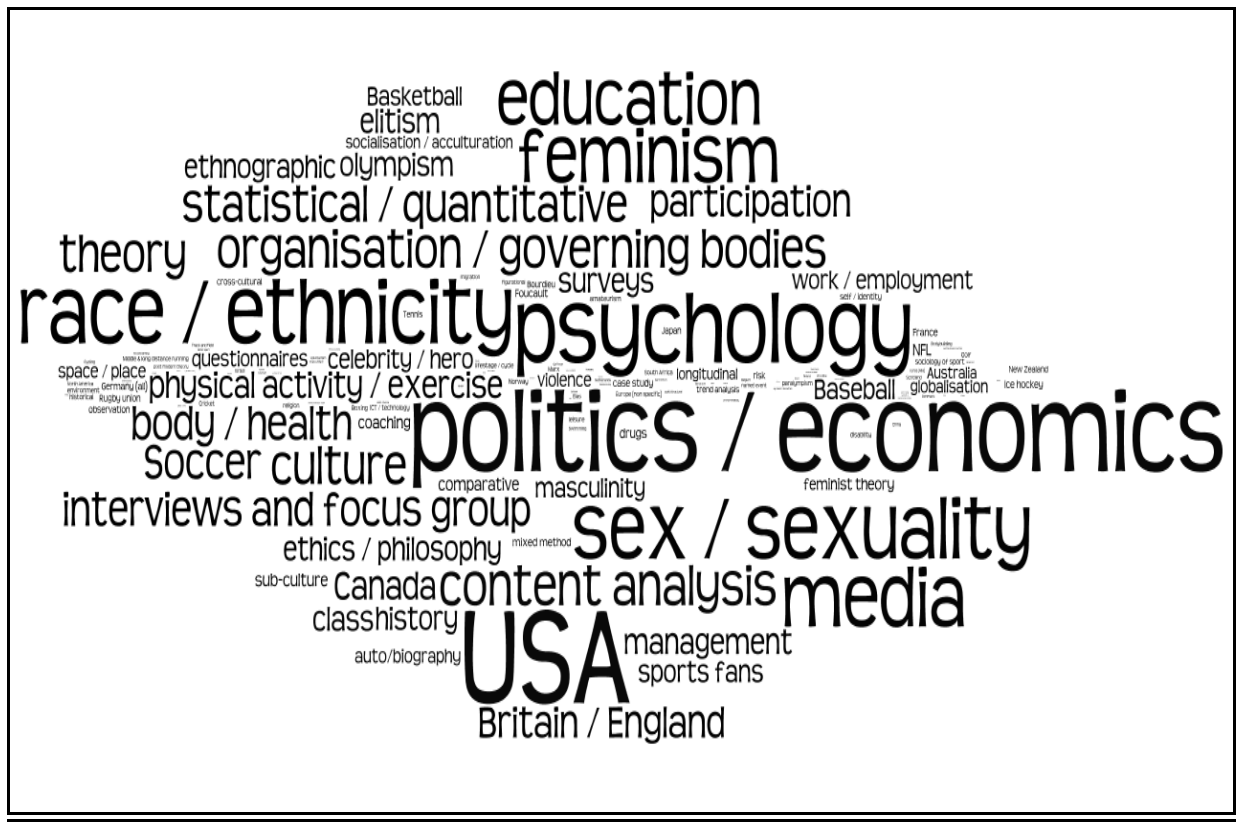

\section{Conclusion}

As noted above, the approach adopted in this study, as with all methodological choices, contains advantages and limitations. This study was based on analysing the title of the paper, the abstract, and the key words which, for some, might be seen as limited in seeking to capture the richness of the research and scholarship taking place. As was noted earlier, those who submit research are being increasingly strategic, not only in their choice of research topic (impact), but also in selecting which words appear in the paper's title and abstract and listed as key words. As was noted previously, if an author chose not to include a particular term, method, theory or suchlike, it does not mean that these were not included in the main paper; what it does suggest is that their absence indicates the author did not see them as being central to their paper. One could overcome this by undertaking a full reading of each paper to analyse the content of the article, but this would be an intensely time-consuming project and beyond the task of most people. One of the original objectives was to identify any paradigm shifts or possible changes in the popularity of terms used; however, 
the number of papers reviewed and the timescale adopted did mean that this level of detail was not realised.

Instead, this paper offers a broad-brush assessment of the content of three of the leading journals that serve the sociology of sport. It is acknowledged that this broad brush does not capture this level of detail and also that a number of other different forms of analysis might have been conducted (for example, on whether the published papers adopted a micro, meso and macro perspective, or exploring the gender of the author or their geographic spread). As noted above, one of the original objectives of this study was to identify longitudinal changes in the use of theory, but similar to the method section above, insufficient data was available to offer a trend analysis or determine any 'paradigm shifts' over the 25 -year period. A more detailed study that looks specifically at the (changing) types of methods and theories employed over time would be a useful addition to the discussion. Any such empirically informed, small-scale study would have the initial advantage of being able to electronically access the archives, although one would still have to manually read and code the paper.

Despite the caveats discussed above, my personal conclusion is that I feel fortunate to be working in a dynamic field or, if preferred, 'effervescent oblivion' (see Carrington, 2010: 10), with a rich diversity of topics and 'journals' (i.e. editors, editorial boards, peer reviewers and authors) working collectively to infuse life-blood and stimulate debate on the social role of sport in contemporary society. The findings can now be subjected to interpretation based on an individual's research interests and career experiences. Hopefully, the data presented in this paper will stimulate a wider critical debate amongst those active within the sociology of sport. Notwithstanding the limitation identified above, the findings offer the first large-scale assessment of the sociology of sport as represented in three of its leading journals. Figure 14 shows an aggregation of the themes, sports, countries, methods and theorists as identified in the title or abstract and/or listed as key words and subject terms and offers 'a footprint' of the three journals' content over a 25 -year time period. How successful the journals have been in acting as the 'life-blood of the discipline' and legitimising the sociology of sport will ultimately depend on what criteria are used to define 'success'. 


\section{$\underline{\text { References }}$}

Aitchison C (2001) Gender and leisure research: The 'codification of knowledge'. Leisure Sciences 23(1): 1-19.

Altbach P and Rapple B (2012) Anarchy and commercialism. Inside Higher Ed. Available at: www.insidehighered.com/views/2012/03/08/essay-problems-state-journal-publishing\# ixzz2663wiUyO (accessed 12 March 2012).

Andrews D (2008) Kinesiology's inconvenient truth: The physical cultural studies imperative. Quest 60(1): 46-63.

Atkinson M (2011) Physical cultural studies [Redux]. Sociology of Sport Journal 28(1): 135-144.

Bairner A (2007) Back to basics: Class, social theory and sport. Sociology of Sport Journal 24: 20-36.

Bairner A (2009) Sport, intellectuals and public sociology: Obstacles and opportunities. International Review for the Sociology of Sport 44: 115-130.

Bishop R (2007) Missing in action: Feature coverage of women's sports in sports illustrated. Journal of Sport \& Social Issues 27(2): 184-194.

BSA/ESRC (2010) International benchmarking review of UK sociology. BSA/ESRC. Available at: http://hapsoc.files.wordpress.com/2010/12/sociology20ibr20report_tcm6-36279.pdf (accessed 7 July 2012).

Burawoy M (2004) Public sociologies: Contradictions, dilemmas and possibilities. Social Forces 82: 603-618.

Byrne D (2012) UK sociology and quantitative methods: Are we as weak as they think? Or are they barking up the wrong tree? Sociology 46(1): 13-24.

Callinicos A (2006) Universities in a Neoliberal World. London: Bookmarks.

Carrington B (2010) Sport, Race and Politics: The Sporting Black Diaspora. London: SAGE.

Coakley J (1987) Sociology of sport in the United States. International Review for the Sociology of Sport 22(1): 63-77.

Collini S (2012) What are Universities for? London: Penguin.

Colquhoun D (2011) Publish-or-perish: Peer review and the corruption of science. The Guardian. Available at: www.guardian.co.uk/science/2011/sep/05/publish-perish-peer-review-science (accessed 5 September 2012).

David M and Sutton C (2011) Social Research. 2nd ed. London: SAGE.

Donnelly P (2005) Editorial: 40th anniversary of the IRSS. International Review for the Sociology of Sport 40(3): 285-288. 
Fanelli D (2010) Do pressures to publish increase scientists' bias? An empirical support from US States Data. PLoS ONE 5(4): e10271. DOI:10.1371/journal.pone.0010271.

Goldstein R (2000) Jack Scott, a prominent critic of sport's excesses, dies at 57. The New York Times. Available at: www.nytimes.com/2000/02/08/sports/jack-scott-a-prominent-critic-ofsports-excesses-dies-at-57.html (accessed 8 February 2012).

Greendorfer S (1987) NASSS. Then and now. Sociology of Sport Journal 4: 289-303.

Harris J (2011) Word clouds considered harmful. Nieman Journalism Lab. Available at: www. niemanlab.org/2011/10/word-clouds-considered-harmful/ (accessed 15 August 2012).

Heck J and Cooley P (1988) Most frequent contributors to the finance literature: 1946-1985. Financial Management 13(3): 209-218.

Heinemann K and Preuss W (1990) 25 years of the international review for the sociology of sport - A content analysis. International Review for the Sociology of Sport 25(1): 3-27.

Hussey T and Smith P (2010) The Trouble with Higher Education: A Critical Examination of our Universities. Abingdon: Routledge.

Ingham A and Donnelly P (1997) A sociology of North American sociology of sport: Disunity in unity, 1965-1996. Sociology of Sport Journal 14(4): 362-418.

Jump P (2012) Research intelligence - REF, get set and go, final rules in hand. Times Higher Education. Available at: www.timeshighereducation.co.uk/story.asp?storycode $=418933$ (accessed 9 February 2012).

Kian E, Mondello M and Vincent J (2009) ESPN - The women's sports network? A content analysis of internet coverage of March madness. Journal of Broadcasting \& Electronic Media 53(3): 477-495.

King C (2007) A text and picture analysis of British national newspaper coverage of the Olympic Games since 1948. International Review for the Sociology of Sport 42(2): 187-199.

Krawczyk Z (1990) Theoretical dilemmas in the sociology of sport. International Review for the Sociology of Sport 25: 41-47.

Krippendorff K (2004) Content Analysis: An Introduction to its Methodology. London: SAGE.

Lapchick R (1977) Arena: The institute for sport and social analysis: Statement of purpose. Arena Review, The Institute of Sport 1: 1.

Loy J and Sage G (1997) Sociology of sport: Traditions, transitions and transformations. Sociology of Sport Journal 14(4): 315-316.

McPherson B (1975) Past, present and future perspectives for research in sport sociology. International Review for the Sociology of Sport 10(1): 55-72.

Malcolm D (2012) The social construction of the sociology of sport: A professional project. International Review for the Sociology of Sport. Epub ahead of print 17 July 2012. DOI: 
Melnick M and Sabo D (1987) Analysis of free communications presented as the first seven NASSS annual meetings: Some patterns and trends. Sociology of Sport Journal (4):

289-297.

Messner M, Dunbar M and Hunt D (2000) The televised sports manhood formula. Journal of Sport \& Social Issues 24: 380-394.

Mills CW (1959) The Sociological Imagination. London: Oxford University Press.

Millward P (2008) Rivalries and racisms: 'Closed' and 'Open' Islamophobic dispositions amongst football supporters. Sociological Research Online 13(6): 5. Available at: www.socresonline. org.uk/13/6/5.html (accessed 7 July 2012).

Moore K (2000) A not-so-radical man: Common sense shaped Jack Scott's views. Sports Illustrated, 21 February. Available at: http://sportsillustrated.cnn.com/vault/article/magazine/ MAG1018320/index.htm (accessed 5 August 2012).

Mumford S (2012) Peer pressure. Times Higher Education, 13 September, 31.

Nixon H (2010) Sport sociology, NASSS, and undergraduate education in the United States: A social network perspective for developing the field. Sociology of Sport Journal 27(1): 76-88.

Riffe D, Lacy S and Fico F (1998) Analyzing Media Messages: Using Quantitative Content Analysis in Research. London: Taylor \& Francis.

Rowe D, McKay J and Lawrence G (1997) Out of the shadows: The critical sociology of sport in Australia, 1986-1996. Sociology of Sport Journal 14(4): 340-361.

Savage M and Burrows R (2007) The coming crisis of empirical sociology. Sociology 41 : 885-899.

Savage $M$ and Burrows R (2009) Some further reflections on the coming crisis of empirical sociology. Sociology 43: 762-772.

Silk M and Andrews D (2011) Toward a physical cultural studies. Sociology of Sport Journal 28(1): 4-35.

Silk M, Bush A and Andrews D (2010) Contingent intellectual amateurism, or, the problem with evidence-based research. Journal of Sport \& Social Issues 34: 105-128.

Silverman D (2003) Interpreting Qualitative Data: Methods for Analysing Talk, Text and Interaction. 2nd ed. London: SAGE.

Smith K and Meer N (2012) REF's effort to make knowledge visible may have cloudy results. Times Higher Education. Available at: www.timeshighereducation.co.uk/story. asp?storycode $=419128$ (accessed 23 February 2012).

Snow CP (2012) The Two Cultures. Cambridge: Cambridge University Press. 
Spender D (ed.) (1981) Men's Studies Modified: The Impact of Feminism on the Academic Disciplines. Oxford: Pergamon Press.

Stemple G (1981) Content analysis. In: Stemple G and Westley B (eds) Research Methods on Mass Communication. Englewood Cliffs, NJ: Prentice Hall, pp. 119-131.

Stoddart B (1989) Sport in the social construct of the lesser developed world: A commentary. Sociology of Sport 6: 125-135.

Thrift N (2005) Knowing Capitalism. London: SAGE.

Tomlinson A (2006) Leisure studies: Progress, phases and possibilities - An interview with Alan

Tomlinson. Leisure Studies 25(3): 257-273.

Uprichard E (2012) Describing description (and keeping causality): The case of academic articles on food and eating. Sociology. Epub ahead of print 23 March 2012. DOI: 10.1177/0038038512441279.

Vincent J (2004) Game, sex, and match: The construction of gender in British newspaper coverage of the 2000 Wimbledon Championships. Sociology of Sport Journal 21(4): 435-456.

Vincent J, Kian E, Pedersen P, et al. (2010) England expects: English newspapers' narratives about the English football team in the 2006 World Cup. International Review for the Sociology of Sport 45(2): 199-223.

Webster F (2006) Cultural studies and sociology at, and after, the closure of the Birmingham School. Cultural Studies 18(6): 847-862.

Williams M, Payne G, Hodgkinson L, et al. (2008) Does British sociology count? Sociology students' attitudes toward quantitative methods. Sociology 42(5): 1003-1021.

'The special issues of the IRSS 22 (in 1987) and 24 (in 1989) discuss the development of Sports sociology in various countries. One can also track discipline trends through the papers delivered at conferences; for example, see the ISSA conferences themes at http://www.issa. otago.ac.nz/confhistory.html.

ii To list all the journals that would be willing to publish a sports-themed paper adopting a social science perspective would be prohibitive.

iii The 'impact factor' assigned to different journals is an (unfortunate) development used to rank journals, not least in the UK's REF exercise. It is difficult to see how this Citation Ranking is anything other than an attempt by Thompson Reuters Institute for Scientific Information to generate additional profits from the higher education sector.

\footnotetext{
${ }^{\text {iv }}$ For example, there were 26 terms relating to education (including education, teaching, students,
} 
school, secondary, college, university, higher, varsity and academic).

${ }^{\vee}$ See also tagxedo.com.

vi One advantage of electronic publishing is that it allows for magnification of the figures.

vii In 2006, Cambridge University admissions tutors defended claims that sport was on their list of 'soft subjects' (see 'PPE good, PE bad?' Available at http://www.guardian.co.uk/education/ 2006/aug/29/highereducation.schools). 